\title{
HISTOPATHOLOGICAL PATTERN OF ENDOMETRIAL BIOPSIES IN PATIENTS WITH ABNORMAL UTERINE BLEEDING ATTENDING BIRAT MEDICAL COLLEGE TEACHING HOSPITAL
}

\author{
Kafle $N^{1^{*}}$, Shaukin $S h^{1}$, Kafle $S U^{2}$, Singh $M^{4}$, Parajuli $S^{5}$
}

\begin{abstract}
Affiliation
1. Lecturer, Department of Pathology, Birat Medical College and Teaching Hospital

2. Associate professor, Department of Pathology, Birat Medical College and Teaching Hospital

3. Assistant Professor, Department of Pathology, Birat Medical College and Teaching Hospital

4. Assistant Professor, Department of Community medicine, Birat Medical College and Teaching Hospital
\end{abstract}

\section{ARTICLE INFO}

Received : 24 May, 2020

Accepted : 28 July, 2020

Published : 05 October, 2020

(c) Authors retain copyright and grant the journal right of first publication with the work simultaneously licensed under Creative Commons Attribution License CC - BY 4.0 that allows others to share the work with an acknowledgment of the work's authorship and initial publication in this journal.

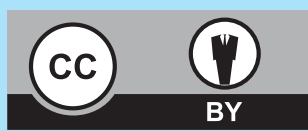

ORA 178

DOI: https://doi.org/10.3126/bjhs.v5i2.31378

* Corresponding Author

Dr. Neeta Kafle

Lecturer

Department of Pathology

Birat Medical College and Teaching Hospital, Biratnagar Email:nitsbipin@gmail.com

ORCID ID: https://orcid.org/0000-0002-2904-8695

\section{Citation}

Kafle N, Shaukin Sh, Kafle SU, Singh M, Parajuli S. Histopathological Pattern of Endometrial Biopsies in Patients with Abnormal Uterine Bleeding Attending Birat Medical College Teaching Hospital. BJHS 2019;5(2)12: 1035-1039.

\section{ABSTRACT}

\section{Introduction}

Abnormal uterine bleeding ( $A \cup B$ ) is one of the commonest gynaecological problems. Etiology of AUB may be structural and functional and varies according to age group. Histological pattern of endometrial sampling along with clinical and radiological findings remains the diagnostic standard for clinical diagnosis of endometrial pathology which ultimately helps in deciding the management of the patients.

\section{Objectives}

To determine histopathological pattern of endometrial biopsies in patients with AUB attending Birat Medical College Teaching Hospital. To determine the pattern of menstrual abnormality in patients with AUB in different age groups

\section{Methodology}

We conducted a prospective hospital based cross sectional study for a period of one year ( $1^{\text {st }}$ April 2019 to March $31^{\text {st }}$ 2020). Histopathological findings of all endometrial biopsy samples in patients with AUB were examined. Patients were categorized into different age groups and the patterns of menstrual abnormality were also documented.

\section{Results}

166 patients presenting with AUB underwent endometrial biopsy. Most of them were of perimenopausal age group $(42.77 \%)$. Menorrhagia was the most common presenting menstrual abnormality. Histopathological examination predominantly revealed normal cyclical endometrium. Hyperplasia was seen more frequently in patients $>40$ years of age. Malignancy was diagnosed in $2.41 \%$, all were adenocarcinoma and was seen in $>50$ years age.

\section{Conclusion}

AUB is a common gynaeco-pathological problem with varied clinical presentation and multiple causes. Functional endometrial changes account for the highest histological pattern. However hyperplasia and malignancy are important cause of AUB in perimenopausal and post menopausal age group's women

\section{KEYWORDS}

Abnormal uterine bleeding, carcinoma, endometrial biopsy, hyperplasia. 


\section{INTRODUCTION}

AUB is one of the commonest gynaecological problems. It is defined as abnormal bleeding different than that of normal menstruation in terms of frequency, duration, amount and bleeding after menopause. It may be due to structural or functional causes. ${ }^{1}$ Fibroids, polyps, endometrial hyperplasia, endometrial carcinoma and complications of pregnancy are the common structural causes of AUB. ${ }^{3}$ Dysfunctional uterine bleeding (DUB) is the functional disorder which is diagnosed only after exclusion of structural, iatrogenic, medications and psychosocial cause. Etiology of AUB varies according to age group affected i.e. reproductive (18-<40years), perimenopausal (40-50years) or post menopausal (>50 years). ${ }^{1}$

The most common investigation for AUB is endometrial biopsy which is done to identify the cause of bleeding. ${ }^{4}$ Histological pattern of endometrial biopsy along with clinical and radiological findings remains the diagnostic standard for diagnosis of endometrial pathology which ultimately helps in deciding the management of patients. Endometrial biopsy is a safe, efficient and cost effective means of evaluating the uterine endometrium. It not only helps to rule out precursor lesion and malignancy but also serves to identify hormonally induced changes, inflammation and other pathology in patients with AUB.

In most patients normal endometrium and inflammatory endometrium are only seen in endometrial biopsy, however, in nearly $40 \%$ of perimenopausal and post menopausal women, presenting with AUB as their only complain, endometrial carcinoma may be found. ${ }^{6}$ Precursor lesions of endometrial carcinoma are endometrial hyperplasia without atypia/ atypical hyperplasia which are also diagnosed with histopathological examination. Hence endometrial biopsy is helpful to exclude precancerous and cancerous lesions.

Detail clinical examination and imaging may help in determining the site and few organic causes but definite diagnosis and clinical management are dependent on the histopathological diagnosis along with classifications of lesions. Thus it holds a very important diagnostic significance. Significant morbidity or mortality can be prevented if endometrial hyperplasia which progresses to malignancy is diagnosed early and treated. This type of study would be valuable in this setting where there has been no published literature. This study was therefore undertaken to determine the histopathological pattern of endometrial biopsies in patients with AUB in different age groups and also to determine patterns of menstrual abnormalities in these patients.

\section{METHODOLOGY}

This is a prospective hospital based cross sectional study done in the Department of Pathology Birat Medical College, Biratnagar, Nepal. All the endometrial biopsy samples in patients with AUB received in the laboratory from $1^{\text {st }}$ April 2019 March $31^{\text {st }} 2020$ were included in the study. Patient's history was documented. Patients with pregnancy related complications, and patients with in-situ intrauterine contraceptives were excluded from the study. All the samples were fixed in $10 \%$ formalin for minimum eight hours then were processed routinely and subsequently stained with Hematoxylin and Eosin (H\&E) stain. Each of the slides was examined by a minimum of two pathologists and then a conclusion was drawn. Histopathological findings were categorized accordingly into proliferative phase, secretory phase, atrophic phase, disordered proliferative endometrium, chronic endometritis, pill induced changes, endometrial polyp, hyperplasia without atypia, atypical hyperplasia and carcinoma. Patients were also categorized into following age groups, Reproductive (18-<40 years), perimenopausal (40-50 years) and post menopausal (> 50 years). ${ }^{1}$ Data collected was analyzed in terms of frequency and age distribution using The Statistical Package for Social Sciences version 20 . The data were presented in frequency tables.

\section{RESULTS}

During a period of one year 166 patients presenting with AUB underwent endometrial biopsy in which the age of the patients presenting with AUB ranged from 27 years to 70 years with a mean of 44 years. A total of 71 (42.77\%) patients presenting with AUB were seen in the perimenopausal age group followed by 63 (37.95\%) patients in the reproductive age group and 32 (19.3\%) patients of the post menopausal age group.

Patients presented most commonly with menorrhagia (58.43\%) followed by post menopausal bleed (19.27\%), metrorrhagia (15.1\%), menometrorrhagia $(4.8 \%)$ polymenorrhea (1.8\%) and oligomenorrhea (0.6\%). (Table 1)

Table 1: Clinical presentation in patients with AUB

\begin{tabular}{|l|c|c|}
\hline Clinical Presentation & Number(n) & Percentage (\%) \\
\hline Menorrhagia & 97 & 58.43 \\
\hline Metrorrhagia & 25 & 15.1 \\
\hline Menometrorrhagia & 8 & 4.8 \\
\hline Polymenorrhea & 3 & 1.8 \\
\hline Oligomenorrhea & 1 & 0.6 \\
\hline Postmenopausal bleeding: & 32 & 19.27 \\
\hline
\end{tabular}

Histopathology of endometrium could be determined in 159 out of 166 patients as 7 biopsies were inadequate for evaluation. Endometrial biopsy revealed normal cyclical pattern endometrium in 95 (57.23\%) patients which included 71 $(42.77 \%)$ patients in the proliferative phase and 24 (14.46\%) in the secretory phase. Non neoplastic conditions like chronic endometritis, disordered proliferative endometrium (Figure1) and pill induced changes were seen in 22 (13.25\%) patients, $9(5.42 \%)$ patients and $3(1.8 \%)$ patients respectively. Endometrial polyp was seen in 4 patients $(2.41 \%)$. Precancerous lesions like endometrial hyperplasia without atypia (Figure 2) were seen in 12 (7.23\%) patients whereas 5 (3.01\%) patients had atypical hyperplasia. Malignancy was diagnosed in $2.41 \%$ and all were adenocarcinoma. (Table 2) (Figure 3) 


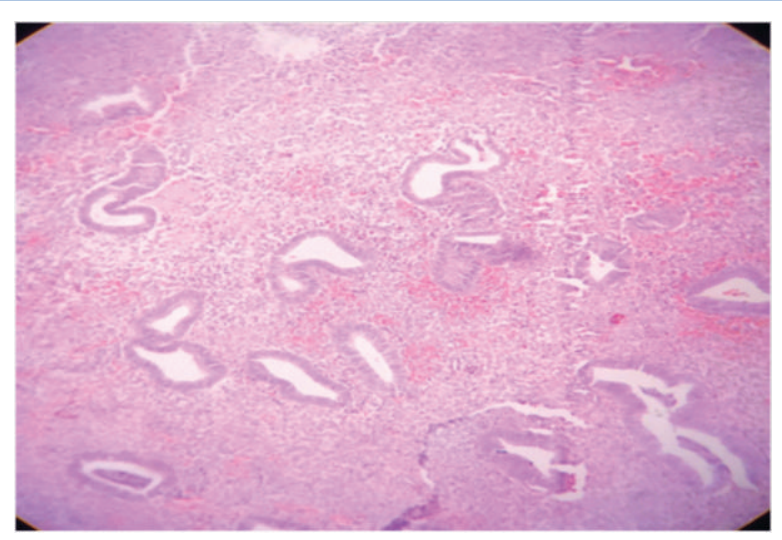

Figure1: Histopathology of disordered proliferative endometrium H\&E stain $x 40 X$

\begin{tabular}{l} 
Table 2: Endometrial biopsy in abnormal uterine bleeding. \\
\begin{tabular}{|l|c|c|}
\hline Histological finding & Number(n) & Percentage(\%) \\
\hline Proliferative & 71 & 42.77 \\
\hline Secretory & 24 & 14.46 \\
\hline Chronic endometritis & 22 & 13.26 \\
\hline Disordered proliferative & 9 & 5.42 \\
\hline Endometrial polyp & 4 & 2.41 \\
\hline Hyperplasia without atypia & 12 & 7.23 \\
\hline Atypical Hyperplasia & 5 & 3.01 \\
\hline Endometrial carcinoma & 4 & 2.41 \\
\hline Pill induced changes & 3 & 1.8 \\
\hline Atrophic & 5 & 3.01 \\
\hline Inadequate sample & 7 & 4.22 \\
\hline
\end{tabular} \\
\hline
\end{tabular}

Figure 2: Histopathology of endometrial hyperplasia without atypia $H \& E$ stain $x 40 X$.

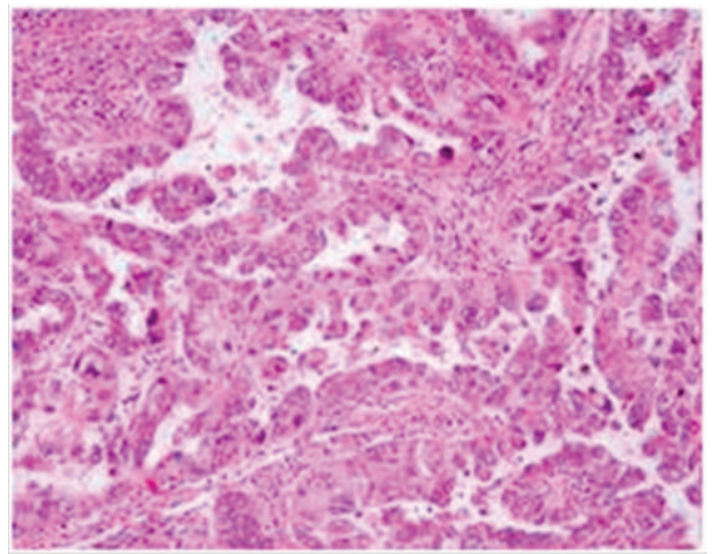

Figure 3: Histopathology of endometroid carcinoma H\&E stain $x 40 X$
Most of the patients of the reproductive age group ( $<40$ years) had normal cyclical pattern of endometrium with 28 patients with proliferative phase endometrium and 13 patients with secretory phase endometrium. Hyperplasia was seen more frequently in patients $>40$ years than patients below 40 years of age. Endometrial carcinoma was seen in $>50$ years age. (Table 3 )

Table3: Endometrial biopsy pattern distribution according
to age.
\begin{tabular}{|l|c|c|c|c|}
\hline Histopathological findings & $<40$ & $\mathbf{4 0 - 5 0}$ & $\mathbf{> 5 0}$ & Total \\
\hline Proliferative & 28 & 35 & 8 & 71 \\
\hline Secretory & 13 & 11 & 0 & 24 \\
\hline Chronic endometritis & 9 & 9 & 4 & 22 \\
\hline Disordered proliferative & 5 & 3 & 1 & 9 \\
\hline Endometrial polyp & 2 & 1 & 1 & 4 \\
\hline Hyperplasia without atypia & 3 & 6 & 3 & 12 \\
\hline Atypical Hyperplasia & 0 & 2 & 3 & 5 \\
\hline Endometrial carcinoma & 0 & 0 & 4 & 4 \\
\hline Pill induced changes & 2 & 1 & 0 & 3 \\
\hline Atrophic & 0 & 0 & 5 & 5 \\
\hline Inadequate sample & 1 & 3 & 3 & 7 \\
\hline
\end{tabular}

\section{DISCUSSION}

AUB is one of the common and challenging problems presenting to gynecologists. It differs from normal menstruation in terms of frequency, duration and amount and also includes post menopausal bleeding. Various factors like fibroids, polyps, hyperplasia, pregnancy related complications, adenomyosis or carcinoma may be the cause. Endometrial biopsy is frequently done in patients with AUB as it is helpful in providing the cause.

In the present study 166 endometrial biopsies were received at the Pathology Department in the period under review. The most common age group presenting with AUB in this study was perimenopausal age group (40-50 years). Similar observations were seen in Vaidya et al, Doraiswami et al. and Jairajpuri et al. ${ }^{1,8,9}$ Increasing number of patients in this age group might be due to the decrease in number of ovarian follicles and their increase in resistance to gonadotrophin hormones with increasing age that leads to low estrogen level which cannot keep normal endometrial growing. ${ }^{10}$ The incidence of AUB in patients with more than 50 years was lower as compared to those between 41 and 50 years. This could be due to early evaluation and treatment thereby decreasing the incidence in later age groups.

Menorrhagia is one of the commonest presentations of AUB. ${ }^{9}$ In our study, pattern of abnormal bleeding include menorrhagia (58.43\%), metrorrhagia ( $25 \%)$, menometrorrhagia (4.8\%) polymenorrhea (1.8\%) oligomennorhea $(0.6 \%)$ and post menopausal bleeding ( $19.27 \%)$. Similar observation was seen in study done by Gupta et al. ${ }^{11}$

Predominant number of patients in our study showed normal physiological changes mainly the proliferative phase (42.77\%) followed by the secretory phase (14.46\%). Bleeding in proliferative phase may be due to anovulatory cycles and in secretory phase due to ovulatory dysfunctional 
uterine bleeding. ${ }^{8}$ Atrophic endometrium was seen in more patients with more than 50 years. Exact cause of this is not known but it is postulated to be due to anatomic vascular variations or local abnormal haemostatic mechanisms where the thin walled veins, superficial to the expanding cystic glands make the vessel vulnerable to injury. ${ }^{8}$ Chronic endometritis was the next common histological pattern seen in $13.26 \%$ of patients. It is commonly seen in patients of reproductive and premenopausal age group and it could be due to the result of complications after use of Intrauterine contraceptive devices or pregnancy related complications. ${ }^{10}$ Disordered proliferative endometrium resembles hyperplasia, but the process is focal. Its incidence varies from $5.7 \%$ to $20.54 \%{ }^{1}$ Diagnosing at early phase helps to prevent the progression of the disease. Nine patients (5.42\%) were diagnosed as disordered proliferative endometrium in our study.

Endometrial polyps have also been associated with AUB. In this study, endometrial polyps were seen in 4 ( $2.41 \%)$ patients which was similar to study done by Gupta et al but is much lower as compared to study by Aslam et al. where they found polyps in $10 \%$ of people. ${ }^{11,12}$ These differences might be probably due to patient selection as their study included all the patients with AUB who underwent transvaginal ultrasonography. Histopathological changes indicative of exogenous hormone effect were seen in 3 $(1.8 \%)$ cases similar to study by Ara et al. but less than study by Vaidya et al. ${ }^{13,1}$

Endometrial hyperplasia was diagnosed in 17 (10.24\%) patients. Similar results were found in study done by Vaidya et al and Gredmark et al. ${ }^{1,14}$ However higher incidences were seen in study done by Bara et al and Muzaffar et al. ${ }^{2,5}$ Hyperplasia has been reported in endometrial biopsies with varied frequency in AUB ranging from $5 \%$ to $18.3 \%{ }^{1,8,9,15}$ Previously endometrial biopsy was classified by the World Health Organization (WHO) on the basis of architectural complexity and cytological atypia- namely simple and complex hyperplasia with and without atypia. ${ }^{16}$ The new WHO classifies hyperplasia into endometrial hyperplasia without atypia and atypical hyperplasia/ endometroid intraepithelial neoplasia. ${ }^{17}$ We recorded $12(7.23 \%)$ patients with hyperplasia without atypia and $5(3.01 \%)$ patients of atypical hyperplasia. Hyperplasia was found to be more frequently in patients above 40 years of age as compared to below 40 years of age. It is important to diagnose hyperplasia as these are precancerous lesions and may progress to carcinoma; atypical hyperplasia with higher risk of progression.
Endometrial biopsy revealed malignancy in 4 (2.41\%) patients which were adenocarcinoma. Higher incidence was found in study by Tiwari et al and Baral et al. ${ }^{4,5}$ A study done by Dangal et al also showed lower incidence of endometroid cancer in Nepalese women possibly due to the practice of early child bearing and multiparity. ${ }^{18}$ The same factors may have possibly contributed to low incidence of carcinoma in our patients. Those endometrial biopsies with scant stroma and fragmented endometrial glands were labeled unsatisfactory as definite diagnosis couldn't be drawn. However, limited literature is available for criteria of adequate and inadequate endometrial samples. ${ }^{9}$

\section{CONCLUSION}

AUB is a common gynaeco-pathological problem with varied clinical presentation and multiple causes. In this present study we conclude that functional endometrial changes account for the highest histological pattern. However hyperplasia and malignancy are important cause of AUB in perimenopausal and post menopausal age.

\section{RECOMMENDATIONS}

The incidence of endometrial hyperplasia and endometrial carcinoma were more common in peri and post menopausal women. Hence, histopathological evaluation is highly recommended in patients of these age groups presenting with $A \cup B$, to rule out the possibility of precancerous and malignant lesions.

\section{LIMITATIONS OF THE STUDY}

The limitations encountered in this study was the inability to include other causes of abnormal uterine bleeding like submucosal fibroid, adenomyosis as endometrial biopsy fail to detect these patients.

\section{ACKNOWLEDGEMENTS}

We are grateful to all the participants of this study. Our special thanks to Department of Gynaecology and obstetrics, Birat Medical College, and Mr Birendra Kumar Roy (Lab Technician) for their help in data collection and management.

\section{CONFLICT OF INTEREST}

None

\section{REFERENCES}

1. Vaidya S, Lakhey M, Sharma P, Hirachand S, Lama S, KC S. Histopathological pattern of abnormal uterine bleeding in endometrial biopsies. Nepal Med Coll J NMCJ. 2013 Mar 1;15:74-7. PMID: 24592801

2. Muzaffar M, Akhtar KAK, Yasmin S, Mahmood-Ur-Rehman null, Iqbal W, Khan MA. Menstrual irregularities with excessive blood loss: a clinico-pathological correlation. JPMA J Pak Med Assoc. 2005 Nov;55(11):486-9. PMID: 16304868

3. Mirza T, Mirza A, Akram S, Aziz S, Mustansar T. Histopathological Pattern of Abnormal Uterine Bleeding in Endometrial Biopsies. J Basic Appl Sci. 2012;8(1) DOI: 10.6000/1927-5129.2012.08.01.25.

4. Tiwari A, Kaur N, Jain S, Rai R, Jain SK. Histopathological Study of Endometrial Biopsy Specimens for Abnormal Uterine Bleeding. J Lumbini Med Coll. 2016;4(2):72-6. DOI: 10.22502/jlmc.v4i2.94

5. Baral R, Pudasaini S. Histopathological pattern of endometrial samples in abnormal uterine bleeding. J Pathol Nepal. 2011;1(1): 13-6. DOI: 10.3126/jpn.v1i1.4443 
6. Tiwari A, Kaur N, Jain S, Rai R, Jain SK. Histopathological Study of Endometrial Biopsy Specimens for Abnormal Uterine Bleeding. J Lumbini Med Coll. 2016;4(2):72-6. DOI: 10.22502/jlmc.v4i2.94

7. Awwad JT, Toth TL, Schiff I. Abnormal uterine bleeding in the perimenopause. Int J Fertil Menopausal Stud. 1993 Oct;38(5): 261-9. PMID: 8298664

8. Doraiswami S, Johnson T, Rao S, Rajkumar A, Vijayaraghavan J, Panicker VK. Study of Endometrial Pathology in Abnormal Uterine Bleeding. J Obstet Gynaecol India. 2011 Aug;61(4):426-30. PMID: 22851826

9. Jairajpuri ZS, Rana S, Jetley S, Nagar H. Atypical uterine bleedingHistopathological audit of endometrium A study of 638 cases. Al Ameen J Med Sci. 2013;6(1):21-8

10. Davey DA, Dysfunctional uterine bledding. In: Whitfield $C R$, ed. Dewhurst's Textbook of Obstretics and Gynaecology for post graduates. Glassgow. blackwell Sciences; 1997.p 590-608.

11. Gupta A, Paitiri K, Gupta A, Gupta R, Khare P. Histopathological patterns in endometrial biopsy associated with abnormal uterine bleeding. Asian Pac J Health Sci. 2018 Jul 1;5:31-6. DOI: 10.21276/ apjhs.2018.5.3.5
12. Aslam M, ljaz L, Tariq S, Shafqat K, Meher-un-Nisa, Ashraf R, et al. Comparison of Transvaginal Sonography and Saline Contrast Sonohysterography in Women with Abnormal Uterine Bleeding: Correlation with Hysteroscopy and Histopathology. Int J Health Sci. 2007 Jan;1(1):17-24. PMID: 21475448

13. Ara S, Roohi M. Abnormal uterine bleeding; Histopathological diagnosis by conventional dilatation and curratage. Professional Med J.2011 Dec;18(4):597-591.

14. Gredmark T, Kvint S, Havel G, Mattsson L-Å. Histopathological findings in women with postmenopausal bleeding. BJOG Int J Obstet Gynaecol. 1995;102(2):133-6.

15. Bhatta $S$, Sinha AK. Histopathological study of endometrium in abnormal uterine bleeding. J Pathol Nepal. 2012;2(4):297-300.

16. Tavasoli FA, Devilee P. (Eds) World Health Organization Classification of tumors. Pathology and Genetics of tumor of breast and female genital organs. IARC Press: Lyon;2000

17. Zaino R, CarinelliSG, Ellenson LH. Tumors of uterine corpus: epithelial tumors and precursors.In:Kurman RJ, Herrington CS et al. WHO classification of tumors of female reproductive organs.IARC Press: Lyon;2014. p. 125-126

18. Dangal G. A study of endometrium of patients with abnormal uterine bleeding at Chitwan Valley. Kathmandu Univ Med J KUMJ. 2003 Jun;1(2):110-2. PMID: 16388208. 